Physical Property Changes in Aging Plutonium Alloys

Brandon W. Chung, Stephen R. Thompson, David S. Hiromoto

March 21, 2008

Materials Research Society

San Francisco, CA, United States

March 24, 2008 through March 28, 2008 
This document was prepared as an account of work sponsored by an agency of the United States government. Neither the United States government nor Lawrence Livermore National Security, LLC, nor any of their employees makes any warranty, expressed or implied, or assumes any legal liability or responsibility for the accuracy, completeness, or usefulness of any information, apparatus, product, or process disclosed, or represents that its use would not infringe privately owned rights. Reference herein to any specific commercial product, process, or service by trade name, trademark, manufacturer, or otherwise does not necessarily constitute or imply its endorsement, recommendation, or favoring by the United States government or Lawrence Livermore National Security, LLC. The views and opinions of authors expressed herein do not necessarily state or reflect those of the United States government or Lawrence Livermore National Security, LLC, and shall not be used for advertising or product endorsement purposes. 


\title{
Physical Property Changes in Aging Plutonium Alloys
}

Brandon W. Chung, Stephen R. Thompson, and David S. Hiromoto

Lawrence Livermore National Laboratory, Livermore, CA 94551

\begin{abstract}
Plutonium, because of its self-irradiation by alpha decay, ages by means of lattice damage and helium in-growth. These integrated aging effects will result in microstructural and physical property changes. Because these effects would normally require decades to measure, studies are underway to asses the effects of extended aging on the physical properties of plutonium alloys by incorporating roughly $7.5 \mathrm{wt} \%$ of highly specific activity isotope ${ }^{238} \mathrm{Pu}$ into the weapons-grade plutonium to accelerate the aging process. This paper presents updated results of self-irradiation effects on enriched and reference alloys measured from the immersion density, dilatometry, and mechanical tests. After nearly 90 equivalent years of aging, both the immersion density and dilatometry show that the enriched alloys at $35^{\circ} \mathrm{C}$ have decreased in density by $\sim 0.19$ $\%$ and now exhibit a near linear density decrease, without void swelling. Both tensile and compression measurements show that the aging process continues to increase the strength of plutonium alloys.
\end{abstract}

\section{INTRODUCTION}

The assessment of aging effects in plutonium lies at the heart of science-based stockpile stewardship $[1,2]$. Plutonium metal in our nuclear stockpile is aging with time because the plutonium undergoes alpha decay, which leads to self-irradiation induced structural damage and chemical changes in the material. The primary aging effects are believed to be lattice damage, helium bubble in-growth, and potential void swelling. Because the effects of interest occur over decades, our approach is to accelerate the effects of radiation damage in plutonium metal by incorporating $7.5 \%$ of the higher specific activity isotope ${ }^{238} \mathrm{Pu}$ into the ${ }^{239} \mathrm{Pu}$ lattice. The objective of this work is to assess the impact of extended aging on the quasi-static properties of plutonium alloys. Changes in quasi-static density and mechanical properties at ambient temperature and pressure are expected due to the aging process. Our past results have shown gradual increase in strength, decrease in density and ductility of plutonium alloys due to aging [3-5]. In this paper we update changes in density and mechanical properties of plutonium alloys due to aging.

\section{EXPERIMENT}

Each dilatometer unit consists of a small vacuum controlled-atmosphere sample chamber fitted with three linear variable differential transducers (LVDTs). The schematic and detailed operations of the dilatometer system are presented elsewhere [3-5], so only a brief description is provided here. An LVDT measures minute changes, 0.1 micron or less, in the position of a push-rod by monitoring changes in the inductance of a detector coil. In the current design, the detector coil is placed outside of the sample chamber. Two different lengths $(2$ and $3 \mathrm{~cm})$ of alloy specimens are used to differentiate between surface oxidation and volumetric swelling in 
the materials. These alloys have nominal gallium concentration of 0.6 weight percentage. These specimens are placed in the copper well located inside the dilatometer system at $35^{\circ} \mathrm{C}$ storage temperatures. A reference low thermal expansion glass (Zerodur) is also placed in the copper well to monitor the stability of the dilatometry system.

The immersion density equipment closely matches a design used by Bowman et al. [6] and uses about $200 \mathrm{ml}$ of Fluorinert Electronic Liquid FC-43 as the immersion fluid. Prior to use, the system is calibrated using NIST glass (SRM 1827A). Because the ${ }^{238} \mathrm{Pu}$-spiked alloys generate heat, a test sample is left overnight in the immersion bath to allow the temperature of the bath to stabilize and the measurements to be reproducible. A correction needs to be applied to the measured density to compensate for the heat generated by the ${ }^{238} \mathrm{Pu}$-spiked sample. Details of density correction are described elsewhere [5].

Each tensile and compression test specimen was dimensionally inspected for the gage diameter and its length (GL), and loaded into a specially designed fixture for the tensile test. With a 0.24 inch GL extensiometer for the strain measurement, all testing was performed at crosshead speed of $0.05 \mathrm{inch} / \mathrm{min}$, so that the ultimate strain rate was about $3.5 \times 10^{-3} / \mathrm{sec}$. Aluminum specimens of known tensile strength were tested to verify the equipment integrity before and after each test specimen. The load and displacement data was recorded on a computer using the Instron Series IX software package in conjunction with an Instron Model 4444 test machine. Data was recorded from preloading until failure. Plutonium specimens for the tensile test have nominal gallium concentration of 0.6 weight percentage.

\section{DISCUSSION}

The dilatometry and immersion density measurements are shown in Figure 1. In order to compare between the dilatometry and immersion density results, the dilatometry data was converted to the density using the measured volume change and estimated change in the specimen's mass from radioactive decay. The time is represented as an equivalent time (in year) obtained by multiplying the measurement time by the accelerating factor (e.g. an initial factor of 18). To calculate this factor, the $\alpha$-decay activities of the ${ }^{238} \mathrm{Pu}$-enriched alloy and the reference alloy are determined using the concentration of isotopes in each alloy. Then the activity of the enrich alloy is normalized to that of the reference alloy to obtain the factor. This accelerating factor will decrease as the material ages due primarily to decreasing concentration of ${ }^{238} \mathrm{Pu}$ in the specimen. The trend in the density change converted from the dilatometry corresponds well to the immersion density during the initial transient state predominately caused by the lattice damage from the radioactive decay. Following the initial state, the rate of density reduction becomes reduced as observed from both the dilatometry and immersion density. The volume change of $\sim 0.19 \%$ (near 90 eq. years of aging) corresponds well with the changes in the immersion density. Both dilatometry and immersion density measurements show dimensional and density changes in enriched $\mathrm{Pu}$ alloys induced by the self-irradiation damage but no evidence of void swelling. 


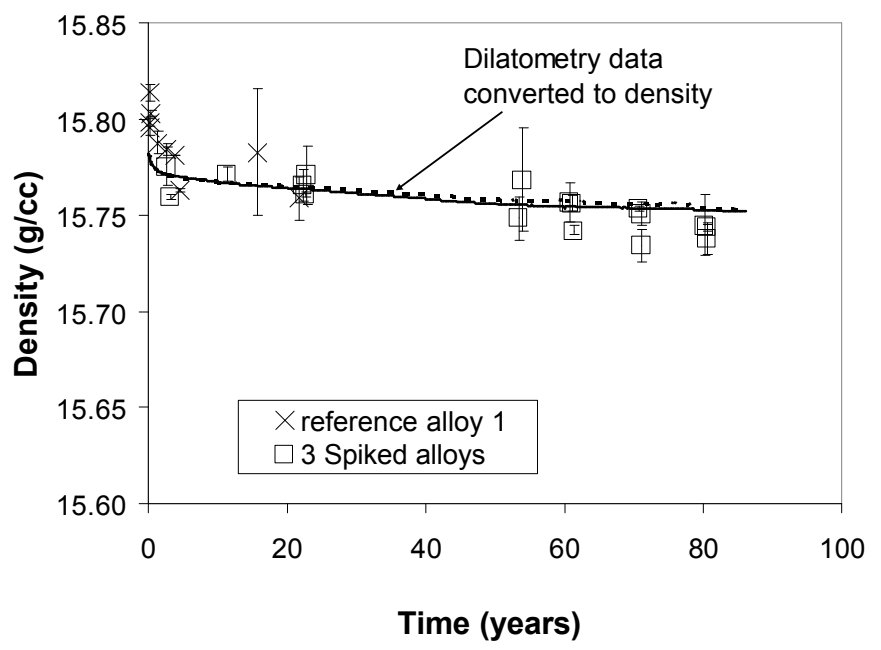

Figure 1. Both dilatometry and immersion density measurements show decrease in the density of plutonium alloys by the aging process.

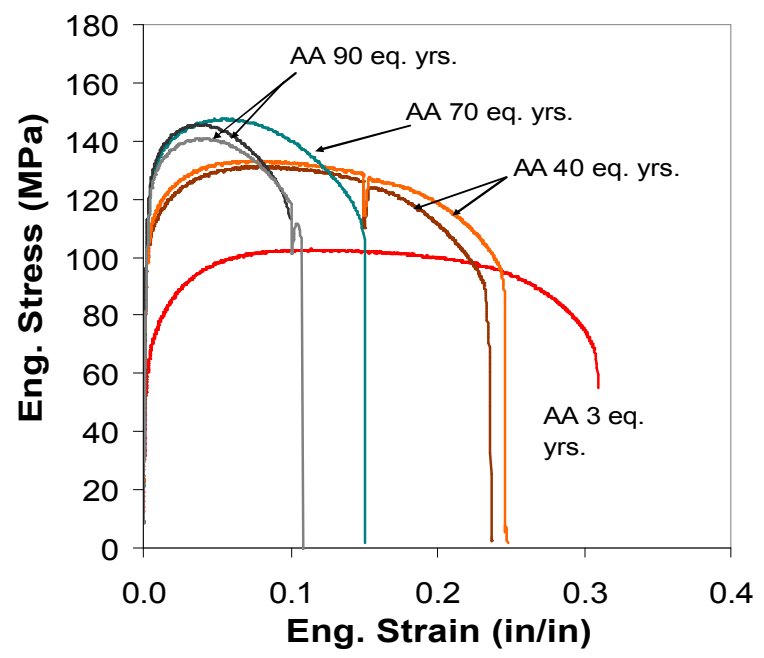

Figure 2. Tensile tests at room temperature show increase in the strength and decrease in the ductility as the enriched alloys are aged.

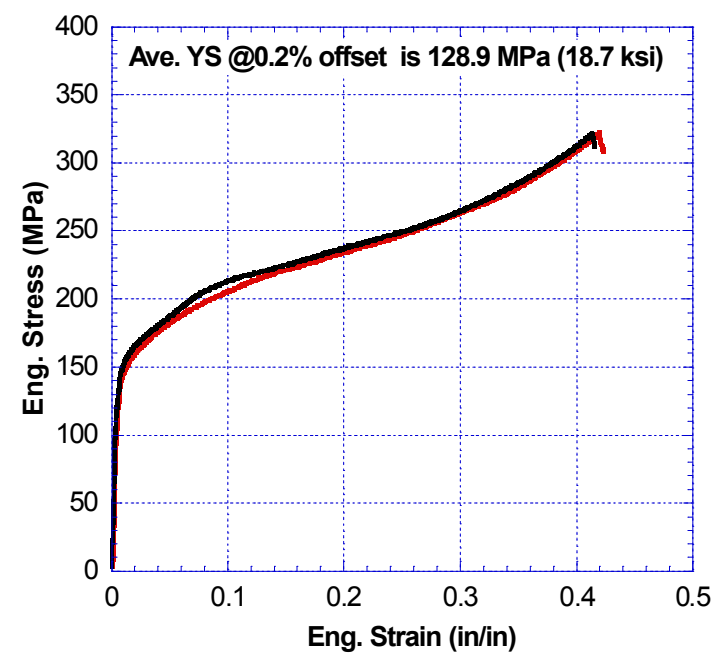

Figure 3. Quasi-static compression tests on enriched alloys aged to $\sim 90$ equivalent years show yields strength similar to the tensile data

Figure 2 shows the stress-strain curves of enriched alloys at 3, 40, 70, and 90 equivalent years, respectively. The yield strength and the engineering ultimate strength of the enriched alloy increase significantly with age. Both the yield strength and the ultimate tensile strength did not change aging from 70 to 90 equivalent years potentially showing saturation of aging effects on the mechanical properties. The Young's modulus is very consistent at near $40 \mathrm{GPa}$ between tested samples irrespective of age.

Figure 3 shows the quasi-static compression data of enriched alloys at 90 equivalent years. The yield strength corresponds closely with the yield strength measured from the tensile test (Figure 2). 


\section{CONCLUSIONS}

The immersion density, dilatometry, mechanical tests are underway on plutonium alloys enriched with 7.5 wt. $\%$ of ${ }^{238} \mathrm{Pu}$ and reference plutonium alloys. Our measurements on aging plutonium alloys continue to show gradual expansion in dimension, decrease in density, increase in strength, and decrease in ductility due to the accumulation of residual lattice damage and helium in-growth.

\section{ACKNOWLEDGMENTS}

This work performed under the auspices of the U.S. Department of Energy by Lawrence Livermore National Laboratory under Contract DE-AC52-07NA27344.

\section{REFERENCES}

1. W.G. Wolfer, Los Alamos Sci., 26 (2000) 274.

2. S.S. Hecker and J.C. Martz, Los Alamos Sci., 26 (2000) 238.

3. B.W. Chung, S.R. Thompson, C.H. Conrad, D.J. Hopkins, W.H. Gourdin, B.B. Ebbinghaus, in: Actinides-Basic Science, Applications, and Technology, L. Soderholm, J.J. Joyce, M.F. Nicol, D.K. Shuh, and J.G. Tobin (Eds), Mater. Res. Soc. Proc., vol 802, Pittsburgh, PA, 2003, p. 39.

4. B.W. Chung, B. Choi, C. Saw, S.R Thompson, C.H. Conrad, D.J. Hopkins, and B.B. Ebbinghaus, in: Actinides 2006-Basic Science, Applications, and Technology, K.J.M. Blobaum, E.A. Chandler, L. Havela, M.B. Maple, M.P. Neu (Eds), Mater. Res. Soc. Proc., vol 986, Pittsburgh, PA, 2006, p. 143.

5. B.W. Chung, S.R. Thompson, C.H. Woods, D.J. Hopkins, W.H. Gourdin, and B.B. Ebbinghaus, J. Nucl. Mater., 355 (2006) 142.

6. H. A. Bowman, et al., J. of Res. Nat. Bur. Stand., $71 \mathrm{C}$ (3), 179 (1967). 